\title{
XPS Depth Study on the Liquid Oxidation of Sn-Bi-Zn-X(Al/P) Alloy and the Effect of Al/P on the Film
}

\author{
X. J. Wang, ${ }^{1}$ N. Liu, ${ }^{1}$ S. Shi, ${ }^{1}$ and Y. X. Chen ${ }^{2}$ \\ ${ }^{1}$ School of Material and Science Engineering, Jiangsu University of Science and Technology, Zhenjiang 212003, China \\ ${ }^{2}$ School of Mechanical and Electrical Engineering, Shanghai Dianji University, Shanghai 201306, China \\ Correspondence should be addressed to X. J. Wang; xjwang.0@163.com and Y. X. Chen; cyx1978@yeah.net
}

Received 7 April 2015; Revised 20 June 2015; Accepted 22 June 2015

Academic Editor: Aziz Dinia

Copyright (c) $2015 \mathrm{X}$. J. Wang et al. This is an open access article distributed under the Creative Commons Attribution License, which permits unrestricted use, distribution, and reproduction in any medium, provided the original work is properly cited.

\begin{abstract}
$\mathrm{X}$-ray photoelectron spectroscopy (XPS) was used to study the properties of liquid oxidation of Sn-Bi-Zn (SBZ) solder alloys and the effect of $\mathrm{Al} / \mathrm{P}$ on the oxide film. The results showed that the oxidation film on SBZ surface was in high concentration of both oxygen and zinc. Adding trace amount of $\mathrm{Al} / \mathrm{P}$ to SBZ alloys (SBZA/ABZP) decreased the ratio of $\mathrm{O} / \mathrm{M}(\mathrm{M}$ could be Sn, $\mathrm{Bi}$, and $\mathrm{Al} / \mathrm{P}$ ) and changed the film compositions. Layers near the free surface of oxidation film mostly contained $\mathrm{Zn}^{2+}$ and $\mathrm{Al}^{3+}$ oxides for SBZA. From the half quantitative analysis result, the aluminum had a surface enrichment behavior in liquid solder, so did phosphorus and zinc. Therefore, the $\mathrm{Al} / \mathrm{P}$ addition changed their stoichiometry such as the ratio of $\mathrm{O} / \mathrm{M}$ near film surface.
\end{abstract}

\section{Introduction}

Due to the step-soldering process in electronic package, solder alloys joining at different temperature ranges have been in demand during manufacturing procedure. Sn-Ag-Cu system, notably, $\mathrm{Sn}-3.0 \mathrm{Ag}-0.5 \mathrm{Cu}$, has been becoming the main stream in surface mount technology (SMT) as a middle-temperature $\mathrm{Pb}$-free solder. Accordingly, $\mathrm{Sn}$-Bi alloy, represented by eutectic $\mathrm{Sn}-58 \mathrm{Bi}$, has been used for thermal module connection in notebook ascribed to the low cost, superior wettability, and almost void-free bonding [1-3]. It can also reduce the damage arising from the mismatch of thermal expansion among various components in electronic assembly [1].

But there are still two issues preventing further application of $\mathrm{Sn}-\mathrm{Bi}$ alloy, that is, lower thermal conductivity and microstructure coarsening with a serious Bi segregation along the interface, which can greatly decrease the reliability of the solder joint [4]. Actually, decreasing Bi-content has been an effective way to adjust the thermal conductivity and melting range. As for the microstructure instability at soldering, temperature can be suppressed by incorporating fine dispersoid particles into $\mathrm{Sn}-\mathrm{Bi}$ alloy $[4,5]$.
Among the alloying elements, $\mathrm{Zn}, \mathrm{Al}$, and $\mathrm{P}$ are very cheap and useful. It is reported that minor $\mathrm{Zn}$ doped in $\mathrm{Pb}$ free solders can obviously inhibit the growth of intermetallic compounds (IMCs), restrain the growth of $\mathrm{Cu}_{3} \mathrm{Sn}$, and suppress the formation of Kirkendall voids during isothermal aging $[6,7]$. About $0.5 \mathrm{wt} . \% \mathrm{Zn}$ addition to $\mathrm{Sn}-\mathrm{Ag}-\mathrm{Cu}-\mathrm{Ce}$ solder alloy can restrain the growth of tin whiskers and strengthen the solder joints [8]. Being very active, $\mathrm{Zn}$ will worsen the oxidation performance of solder alloy during and after soldering. Element alloying has been an effective way to improve the antioxidant power of $\mathrm{Zn}$-containing solders [9]. Al, Ag, and In addition can improve the liquid oxidation behavior at $\mathrm{Sn}-\mathrm{Zn}$ alloy [9-12]. Furthermore, Al decreases the oxidation rate while doping in $\mathrm{Sn}-\mathrm{Zn}$ alloy due to the formation of $\mathrm{Al}_{2} \mathrm{O}_{3}$ thin film on the surface, which is much similar to $\mathrm{Bi}, \mathrm{Ga}$, and $\mathrm{P}$ for $\mathrm{Sn}-\mathrm{Zn}$ solders $[12]$. Since $\mathrm{Al}$ and $\mathrm{P}$ have been paid much attention for the cheapness and effectiveness, Sn-40Bi-2Zn (SBZ) and Sn-40Bi-2Zn-X (X could be Al and P, simplified as SBZA and SBZP, resp.) will be used to investigate the effect of minor $\mathrm{Al} / \mathrm{P}$ addition on the oxidation performance of SBZ alloy. As regards the testing method, using XPS in the characterization of formed metal alloy surface is not 
new $[13,14]$. Many efforts focusing on oxide formation on iron, steel, and molten tin have been implemented [13-15].

\section{Experimental Procedures}

2.1. Preparation of Specimens. SBZ, SBZA, SBZP, and Sn-58Bi alloys (for comparison in oxidation observation by eye) were prepared using pure $\mathrm{Sn}, \mathrm{Bi}, \mathrm{Zn}, \mathrm{Al}$, and $\mathrm{P}$ in vacuum oven at $800^{\circ} \mathrm{C}$ and remelted with stirring at $200^{\circ} \mathrm{C}$ to obtain a homogenized solder alloy. During the remelting process, an antioxidation agent was used to protect the liquid solder from oxidation. Subsequently, the solder alloys were aged for two weeks in room temperature for a stabilized microstructure.

\subsection{Surface Observation of Solder Alloy after Oxidation.} About $40 \mathrm{~g}$ solder alloys were put in graphite crucibles with a diameter of $28 \mathrm{~mm}$ and heated up to $170 \pm 5^{\circ} \mathrm{C}$ to observe the oxidation processes during $1 \mathrm{~h}$ in air. The first dross should be carefully scraped away from the initial liquid surface to leave a fresh surface for oxidation starting therefrom. The color changes of the liquid solder surface with oxidation time increasing were observed visually and the final appearance of the oxide films was recorded by a digital camera.

2.3. XPS Procedure. Solder alloys were exposed at $170 \pm 5^{\circ} \mathrm{C}$ for $7 \mathrm{~min}$ before cooling down to achieve oxidized surfaces. The solid samples were cut from the top surface of the ingots into about 2-3 $\mathrm{mm}$ sheets for XPS tests. For the test is sensitive to pollution, all the samples should be kept carefully away from contaminations.

The surface elementary and chemical analyses were carried out via XPS with an achromatic $\mathrm{Al} \mathrm{K}_{\alpha}$ X-ray source. After the original surface of samples was analyzed, an argon ion beam with $0.2 \mu \mathrm{A}$ current operating at $3 \mathrm{keV}$ was used to etch away a very thin layer of the solder from the oxidation surface to expose the underlying layer. Subsequently, a second surface analysis of the newer oxide film was performed by XPS with an argon gun attached to. So, repeatedly, an etch rate of about $0.6 \mathrm{~nm} / \mathrm{s}$ was motivated over a $2 \mathrm{~mm} \times 2 \mathrm{~mm}$ area by the manner the same as [16].

2.4. XSP Data Analysis. The etching and measurement for each sample were operated about 10 times till the oxygen content test on the surface becomes near to zero. All the spectra were calibrated by carbon adsorbed on the initial surface of the sample during etching.

Curve fitting processes for all high-resolution spectra were implemented by the XPS Peak-Fitting ProgrammeXPSPEAK4.1 to deconvolute and quantify the contribution of each chemical species (element associations) that comprise the spectra.

\section{Results and Discussion}

3.1. Observation of Liquid Solder Alloy. Liquid Sn-58Bi alloy is easily oxidized in atmosphere condition. The freshly displayed surface remained silver-white for about $7 \mathrm{~min}$ before a gray white film formed. Then, the color of the liquid solder alloy varies from gray, blue with inhomogeneous purple, and finally dark blue with a light brownish yellow in some areas within $1 \mathrm{~h}$ (Figure $1(\mathrm{a})$ ). In the same air exposure condition, Zn-containing solder alloy, SBZ loses metallic lustre after about $3 \mathrm{~min}$ and keeps in white with a slight blue finally. The solder surface is quite rough due to the $\mathrm{Zn}$ oxidation before, during, and after cooling down, as shown in Figure 1(b).

SBZP and SBZA solder alloys shine with grey or dark grey metallic lustre in liquid state within $1 \mathrm{~h}$ of exposure in air. With increasing oxidation time to about $30 \mathrm{~min}$, an oxidation film with a slight grey white is visible on SBZP liquid surface, while the color on SBZA surface shows somewhat blue. After cooling down to room temperature, the surface grows rough on the surface of SBZP solder alloy (Figure 1(c)). In comparison, the metal surface of SBZA still keeps smooth in solid state, as shown in Figure 1(d).

\subsection{The Variation of Atomic Concentration with Etch Time.} The variation in chemical composition with etch time of tin, oxygen, bismuth, zinc, and aluminium or phosphorus obtained from the XPS survey scans for the three specimens (SBZ, SBZA, and SBZP) is shown in Figure 2. The oxygen content on the outer surface among three specimens decreases by the turn of SBZ, SBZP to SBZA from about 70 at. $\%$ to 60 at.\% and then 45 at.\% (see Figure 2(a)). It indicates that the oxidation film of SBZ is much porous. Moreover, the total thicknesses of the oxide films after oxidation at $170^{\circ} \mathrm{C}$ for $7 \mathrm{~min}$ are about $156 \mathrm{~nm}$ for SBZA sample and $216 \mathrm{~nm}$ for SBZ and SBZP alloys deduced from oxygen content.

As observed in Figures 2(b) and 2(c), for tin and bismuth as the main elements, their concentrations increase with etch time as expected. The concentrations of zinc, aluminium, and phosphorus oppositely follow an increase sharply and then decrease towards the solder base direction. Among the three alloys, it is worth noting that the $\mathrm{Zn}$ concentration on the top of the oxidation film decrease followed by SBZ, SBZP to SBZA in turn corresponding to 40.4 at.\%, 36.9 at.\%, and 24.6 at.\%, respectively. It indicates that a trace amount of $\mathrm{Al} / \mathrm{P}$ doping in SBZ solder can protect $\mathrm{Zn}$ from overoxidation, as shown in Figures 2(d) and 2(e). Furthermore, $\mathrm{Zn}$ is somewhat enriched at the area of near surface, also the outer surface compared to the base-alloy composition. Accordingly, the contents of $\mathrm{Al}$ and $\mathrm{P}$ are thousand times more than additive amount, which suggests that the two elements have strong surface enrichment behavior in liquid solder alloy. Thus, there are three peaks showing $\mathrm{Zn}, \mathrm{Al}$, and $\mathrm{P}$ at low etching time. It can be ascribed to the following three points. First, element O, especially the absorbed oxidation, makes the other element contents keep lower relatively; second, the chemical O keeps driving $\mathrm{Zn}$ and $\mathrm{Al} / \mathrm{P}$ diffusion from the solder base to react into compounds; finally, the competition between the above two reasons may result in the highest contents emerging at the sublayer of the oxidation films.

The ratios of metal element $\mathrm{M}$ ( $\mathrm{M}$ could be metal element in samples) and oxygen on the surface are about $3: 7,4: 6$, and $4.5: 5.5$ for SBZ, SBZP, and SBZA, respectively, increasing rapidly to $6: 4$ after etching for $40 \mathrm{~s}$ with argon ions for SBZ 


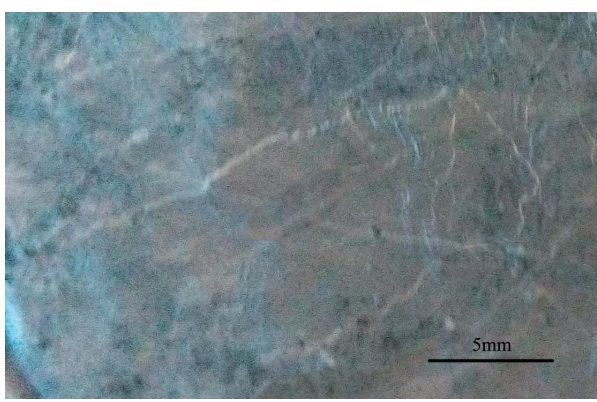

(a)

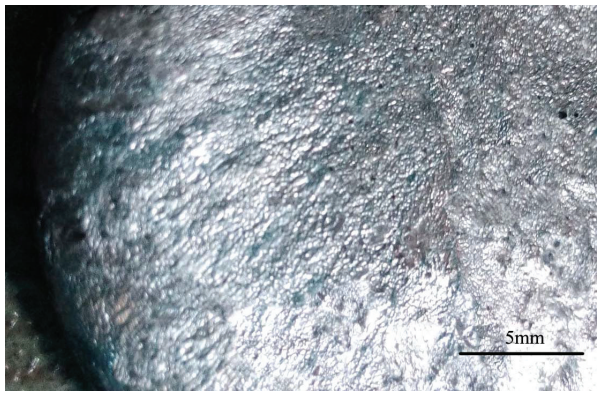

(c)

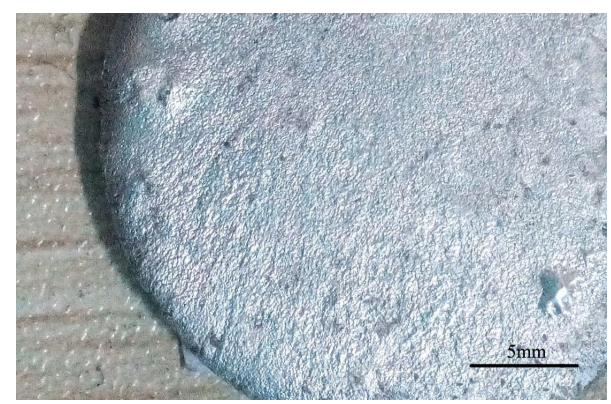

(b)

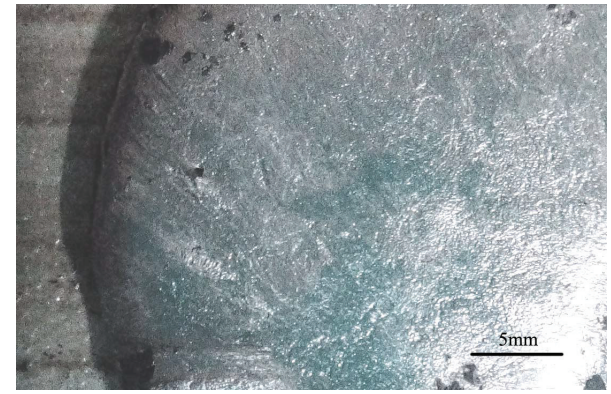

(d)

FIGURE 1: Oxidation appearances of (a) Sn-58Bi, (b) Sn-40Bi-2Zn, (c) Sn-40Bi-2Zn-0.005P, and (d) Sn-40Bi-2Zn-0.005Al after exposure in air at $170^{\circ} \mathrm{C}$ for $1 \mathrm{~h}$.

sample and $10 \mathrm{~s}$ for the latter two samples. It indicates the metal elements oxidation in SBZ is much serious compared to the elements in SBZA and SBZP. As for the species of the oxides, it is hard to distinguish them only from the semiquantitative results. And there are two other issues that should also be taken into account in the analysis. Firstly, there are at least four species of elements in the sample alloys which need further high-energy spectra analysis to conform the chemical states of the elements. Secondly, the surface oxygen should conclude both the physical adsorption oxygen and the chemical state oxygen appearing in oxides of metal M. Therefore, the O 1s, Sn 3d, Zn 2p, and so forth spectra should be analysed in detail, respectively, considering that $\mathrm{Al}$ addition cannot only protect $\mathrm{Zn}$ from oxidation but also reduce the thickness of oxidation film, while trace amount of $\mathrm{P}$ doping into SBZ only protects the $\mathrm{Zn}$ from overoxidation. Therefore, the XPS spectra of elements in SBZ and SBZA samples have been chosen for further analyses in the following section.

3.3. Analyses for SBZ. Figure 3 shows the O 1s spectra of SBZ sample etched at various times along the film depth direction, which are decomposed to one or two symmetric peaks using a Shirley background type of subtraction for fitting the original asymmetric peaks through Gaussian curves.

The deconvoluted $\mathrm{O}$ 1s peaks are located at 530.6 (A) and 532.6 (B) eV for etch time of $0 \mathrm{~s}$, corresponding to the spectral factoring of $\mathrm{O}$ chemically bound with metal element $\mathrm{M}$ and the adsorbed oxygen, respectively. Peak A might be assigned to the presence of metal oxide (OM oxide) [17]. Peak B has been reported to correspond to presentation of adsorbed oxygen [15]. It is obvious that the amount of adsorbed oxygen is much higher than that of $\mathrm{O}$ chemically bound with metal M. After etching for $60 \mathrm{~s}$ (Figure 3(b)), the adsorbed oxygen on surface is very low and entirely removed within $80 \mathrm{~s}$, producing a symmetrical and sharp peak pattern shown in Figure 3(c). It is worthwhile to note that the peak A in Figure 3(a) shifts from $530.6 \mathrm{eV}$ to $530.9 \mathrm{eV}$ after $60 \mathrm{~s}$ etching, which might be resulting from the stronger covalence of $\mathrm{Sn}-\mathrm{O}$ bond.

The XPS patterns of $\mathrm{Sn} 3 \mathrm{~d}$ peaks for SBZ sample at different depths in the oxide film are shown in Figure 4. There are two kinds of chemical states of tin: tin oxides and metallic tin. The peak position of metallic tin, $\mathrm{Sn}^{0}$, is located at $484.8 \mathrm{eV}$, while the peaks standing for tin oxides are showing at $486-487.1 \mathrm{eV}$. For the difference of peak positions between $\mathrm{Sn}^{2+}$ and $\mathrm{Sn}^{4+}$ is so small that their states cannot be distinguished from each other. With etching time increasing, the proportion of tin oxide decreases and the peak position of Sn $3 \mathrm{~d} 5 / 2$ spectrum gradually shifts from $484.5 \mathrm{eV}$ (tin oxides) to $485 \mathrm{eV}$ (metallic tin).

Figure 5(a) displays $\mathrm{Zn} 2 \mathrm{p}$ spectra which possess two peaks corresponding to $1021.6 \mathrm{eV}(\mathrm{Zn} 2 \mathrm{p} 3 / 2)$ and $1048.1 \mathrm{eV}$ $(\mathrm{Zn} 2 \mathrm{pl} / 2)$, respectively. One thing to be noted is that there is a small shift of the $\mathrm{Zn} 2 \mathrm{p} 3 / 2$ peaks to the left after etching for $60 \mathrm{~s}$. This peak shift could be ascribed to the chemical state change of $\mathrm{Zn}$ in the oxides, from $\mathrm{ZnO}$ to $\mathrm{Zn}$ metal according to the data in Table 1.

And $\mathrm{Bi} 4 \mathrm{f}$ spectra include a doublet structure generated by the splitting of multiplet (i.e., Bi 4f7/2 and $\mathrm{Bi} 4 \mathrm{f} 5 / 2$ ) shown in Figure 5(b). Based on the binding energies reported in previous studies in Table 1 and NIST Standard Reference Database, Bi compounds of the film in this study can be classified into two types as $\mathrm{Bi}$ metal and $\mathrm{Bi}_{2} \mathrm{O}_{3}$ corresponding 


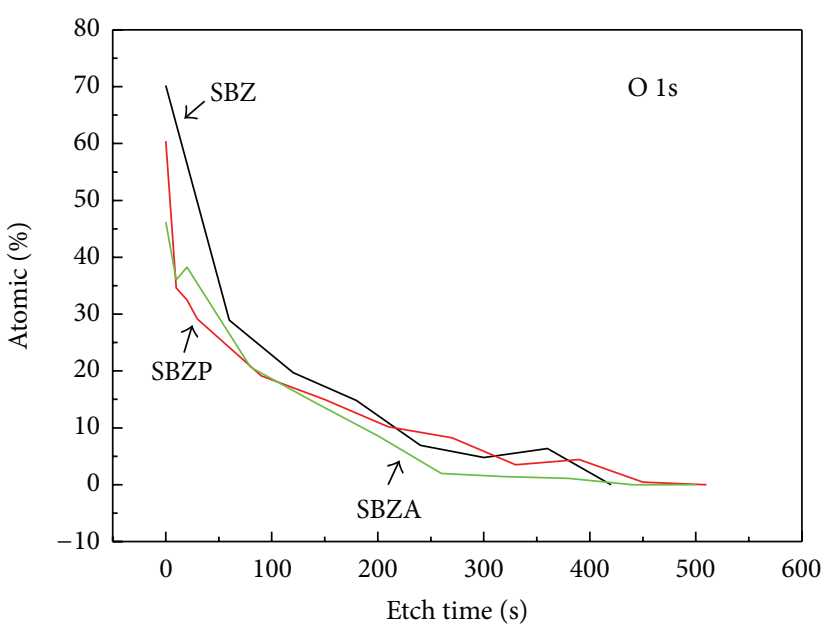

(a)

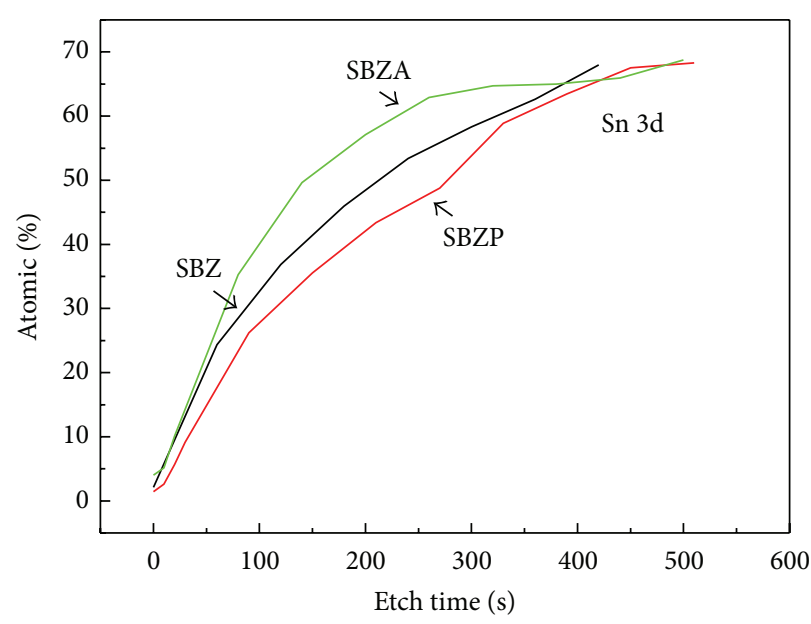

(c)

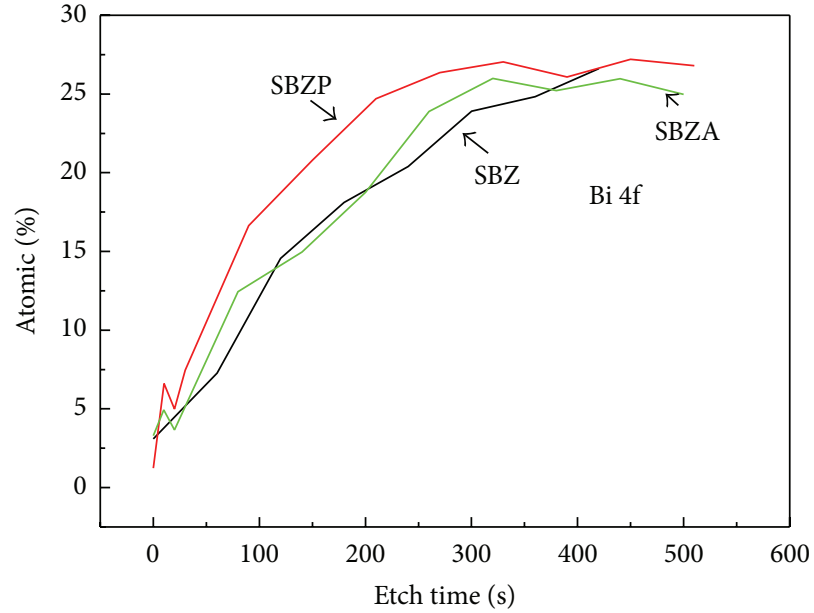

(b)

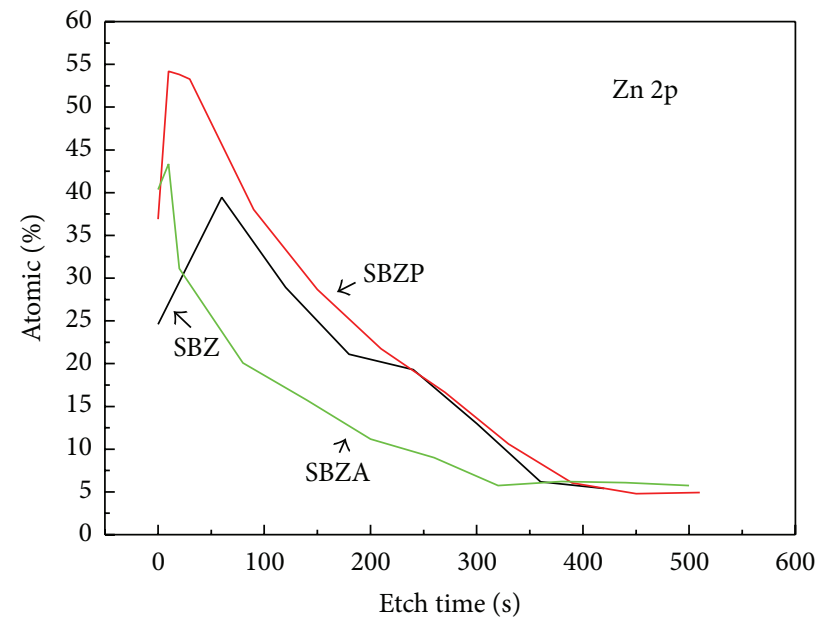

(d)

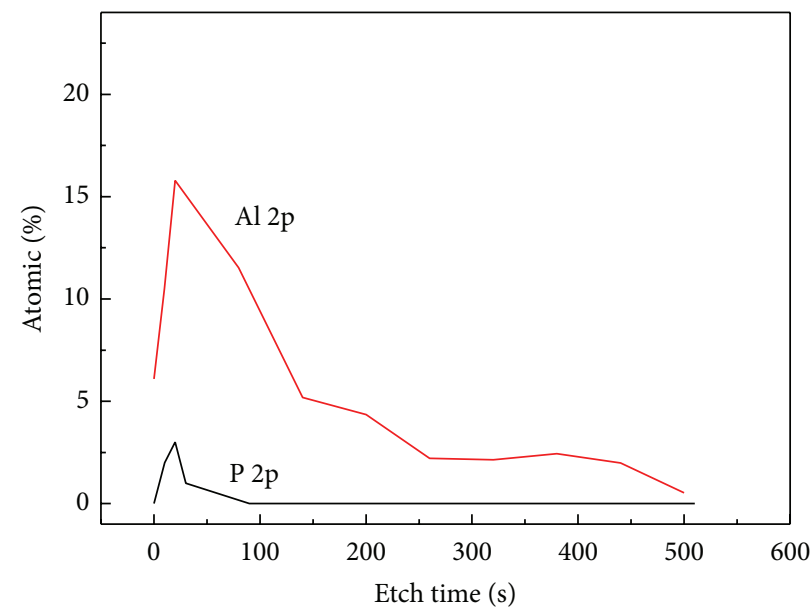

(e)

Figure 2: XPS depth profiles (at.\%) for (a) oxygen, (b) zinc, (c) tin, (d) bismuth, and (e) aluminium and phosphorus recorded for the SBZ, SBZA, and SBZP specimens. 


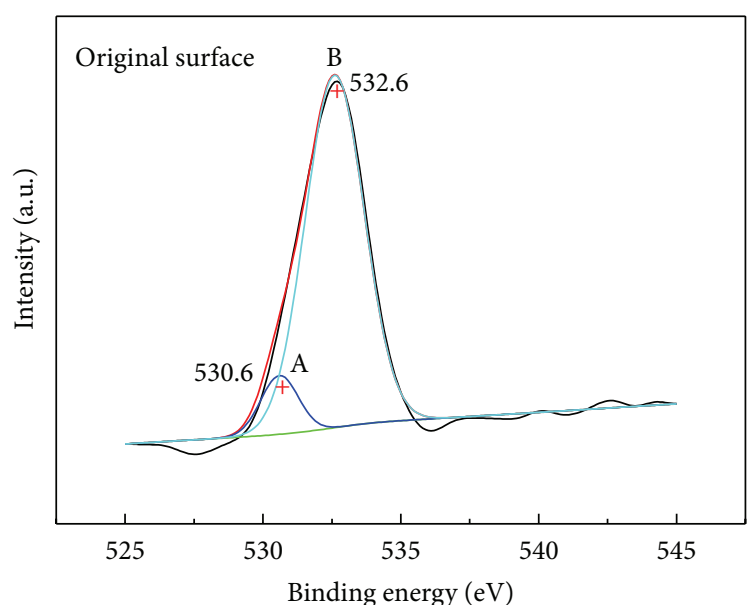

(a)

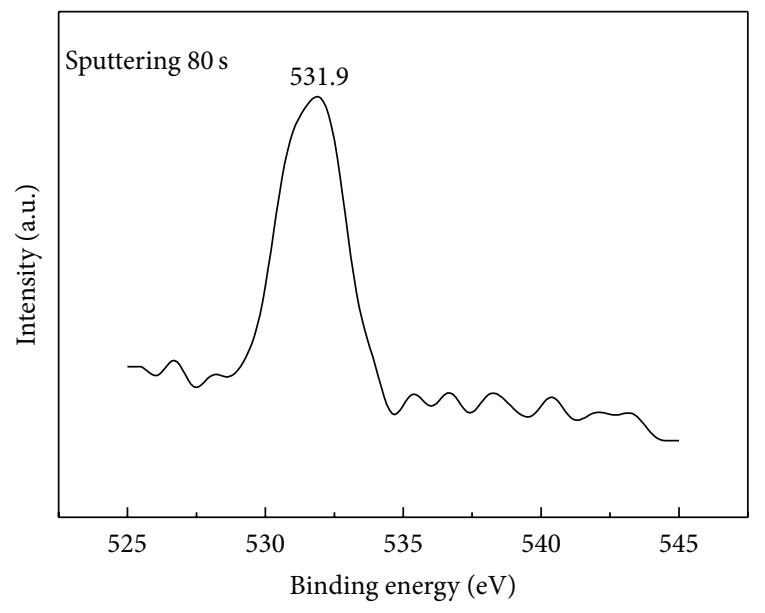

(c)

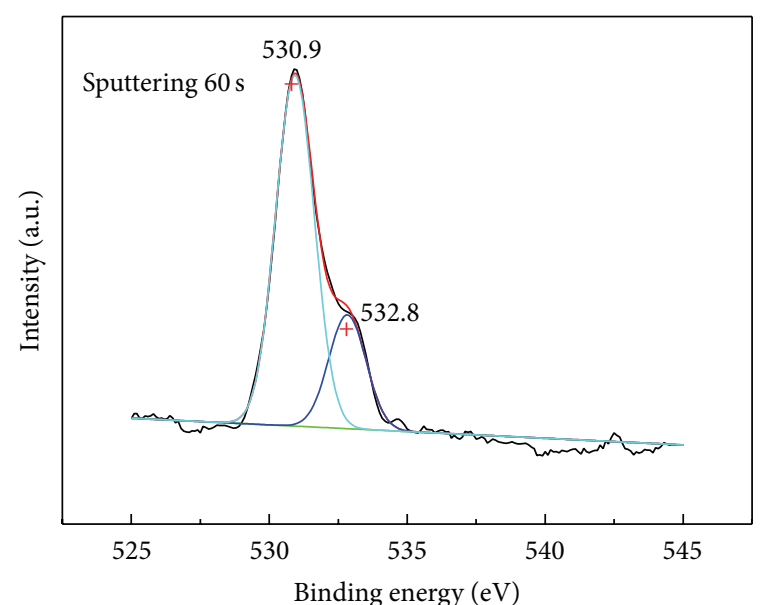

(b)

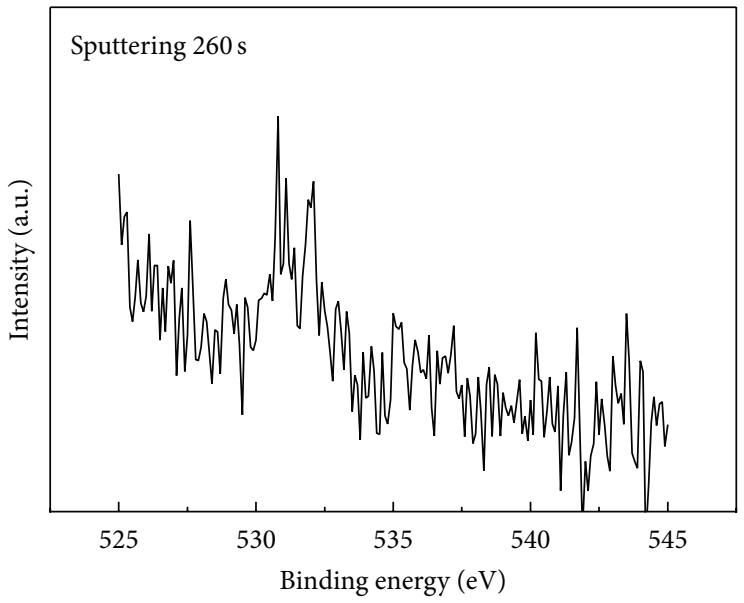

(d)

FIGURE 3: $\mathrm{O}$ 1s spectra of SBZ sample exposure at $170^{\circ} \mathrm{C}$ for $7 \mathrm{~min}$ after etching for (a) $0 \mathrm{~s}$ (initial surface), (b) $10 \mathrm{~s}$, (c) $80 \mathrm{~s}$, and (d) $260 \mathrm{~s}$.

TABLE 1: XPS binding energy values for solder elements and the oxidative products obtained from literatures (Al, O data from NIST Standard Reference Database 20, V. 3.5).

\begin{tabular}{|c|c|c|c|c|c|}
\hline & Sn $3 d 5 / 2(e V)$ & $\mathrm{Zn} 2 \mathrm{p} 3 / 2(\mathrm{eV})$ & $\mathrm{Bi} 4 \mathrm{f} 7 / 2(\mathrm{eV})$ & $\mathrm{Al} \mathrm{2p}(\mathrm{eV})$ & O 1s \\
\hline Sn [15] & 484.8 & & - & & \\
\hline $\mathrm{SnO}[15,19]$ & $486.6 / 486$ & & - & & 530.1 \\
\hline $\mathrm{SnO}_{2}[15,19]$ & $486.4 / 487.1$ & & & & 531.0 \\
\hline $\mathrm{Zn} \mathrm{[20]}$ & & 1021.45 & & & \\
\hline $\mathrm{ZnO}[20]$ & & 1021.7 & & & 530.7 \\
\hline $\mathrm{Bi}[10]$ & & & 156.8 & & \\
\hline $\mathrm{Bi}_{2} \mathrm{O}_{3}[10,17]$ & & & 159.5 & & 529.8 \\
\hline $\mathrm{Al}[21]$ & & & & 73 & \\
\hline $\mathrm{Al}_{2} \mathrm{O}_{3}[18]$ & & & & $76-77$ & 532.6 \\
\hline O [15] & & & & & 532.5 \\
\hline
\end{tabular}

to the peak binding energies around $157 \mathrm{eV}$ and $158 \mathrm{eV}$, respectively $[10,17]$.

3.4. Analyses for SBZA. The O 1s spectra of SBZA sample along the depth of the oxide film are shown in Figure 6. The deconvoluted $\mathrm{O} 1 \mathrm{~s}$ peaks for original surface are located at 531 $\left(\mathrm{A}^{\prime}\right) \mathrm{eV}$ and $532.6\left(\mathrm{~B}^{\prime}\right) \mathrm{eV}$. Based on the results in Figure $3, \mathrm{~A}^{\prime}$ peak can be assigned to metal oxide (OM oxygen), and the latter $\mathrm{B}^{\prime}$ may relate to the adsorbed oxygen like SBZ alloy and the emerging $\mathrm{Al}_{2} \mathrm{O}_{3}$ [18]. However, $\mathrm{B}^{\prime}$ peak disappears after $20 \mathrm{~s}$ of etching. It should be the absorbed oxygen mainly. The binding energy of peak $\mathrm{A}^{\prime}$ is $0.4 \mathrm{eV}$ higher than the position of peak A in SBZ sample, which may indicate the species changes of oxides in the outmost surface of the film. 


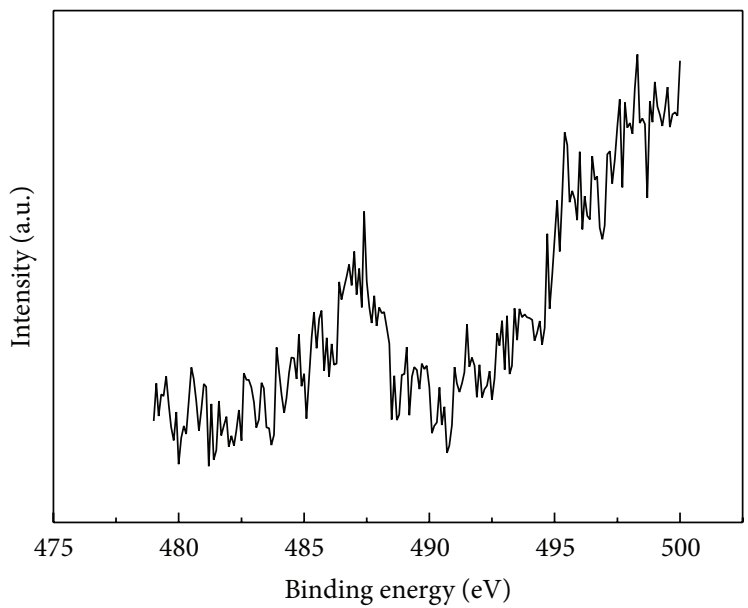

(a)

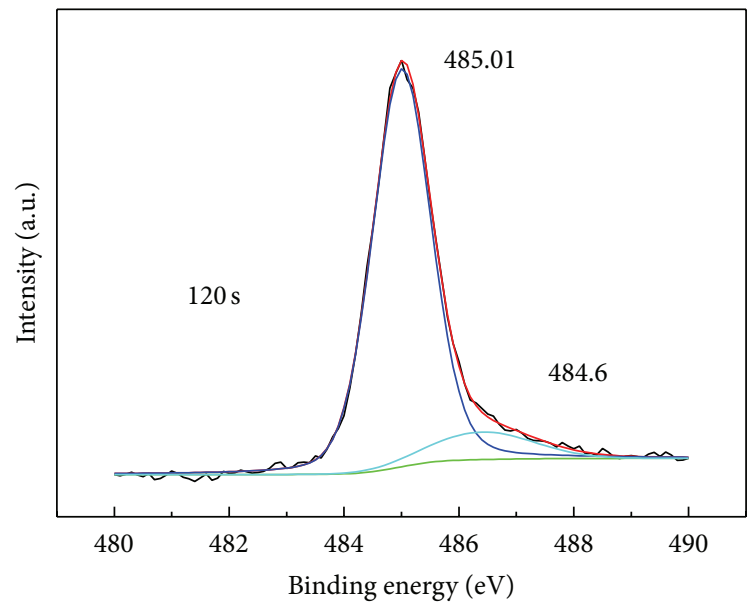

(c)

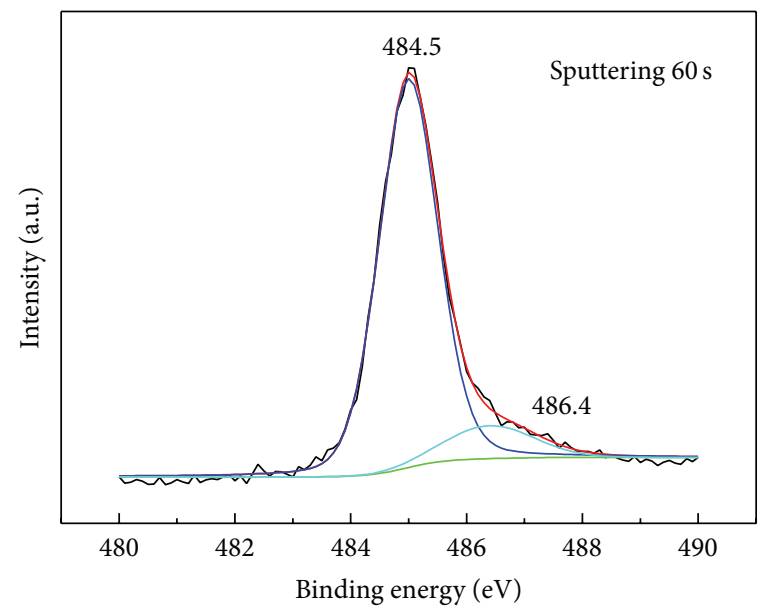

(b)

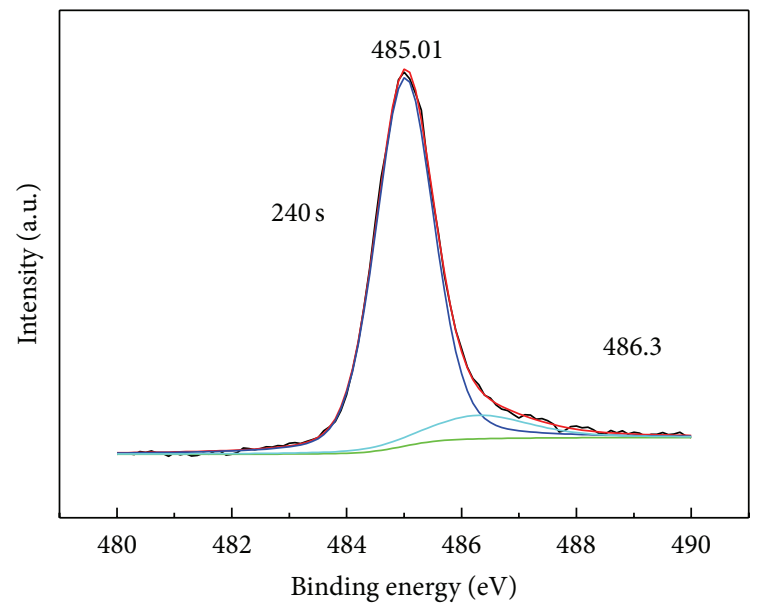

(d)

Figure 4: Sn 3d5/2 spectra of SBZ sample exposure at $170^{\circ} \mathrm{C}$ for $7 \mathrm{~min}$ after etching for (a) $0 \mathrm{~s}$ (initial surface), (b) $10 \mathrm{~s}$, (c) $140 \mathrm{~s}$, and (d) $260 \mathrm{~s}$.

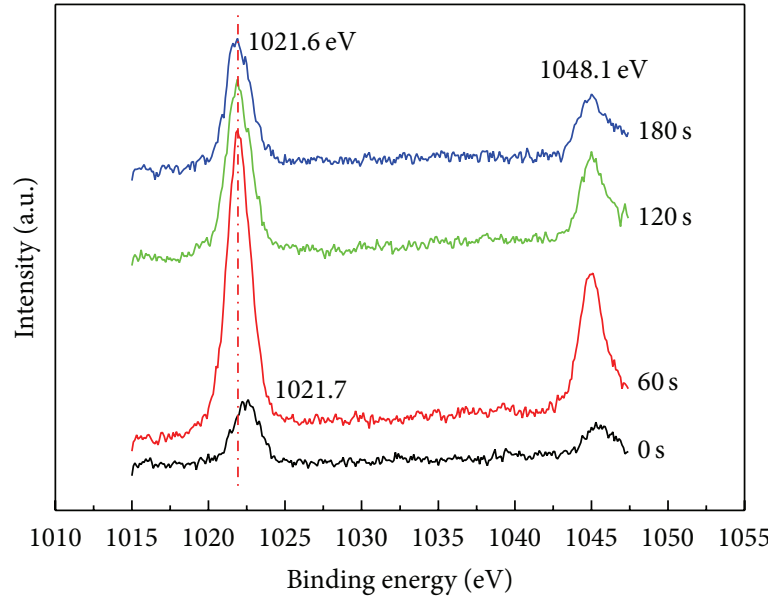

(a)

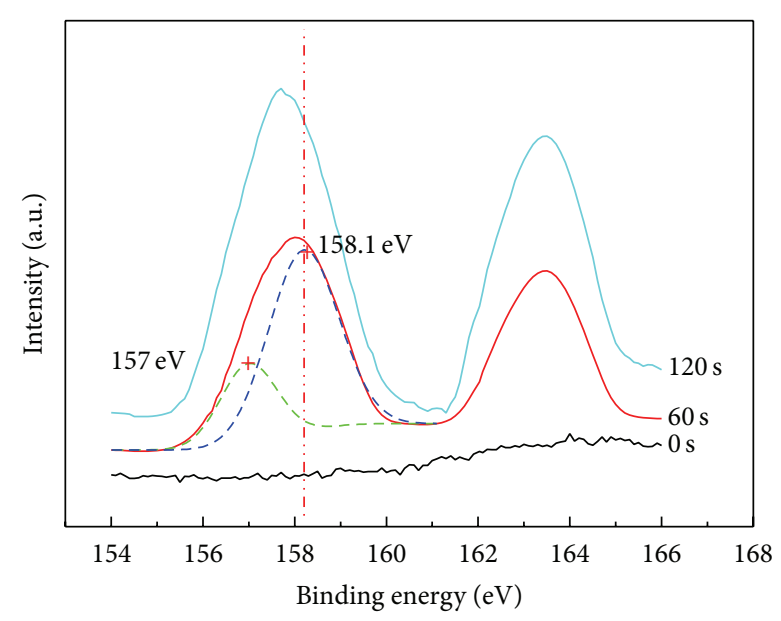

(b)

FIgURE 5: Spectra of (a) $\mathrm{Zn} 2 \mathrm{p}$ and (b) Bi $4 \mathrm{f}$ in $\mathrm{SBZ}$ sample oxidized at $170^{\circ} \mathrm{C}$ for $7 \mathrm{~min}$ after etching for various time. 


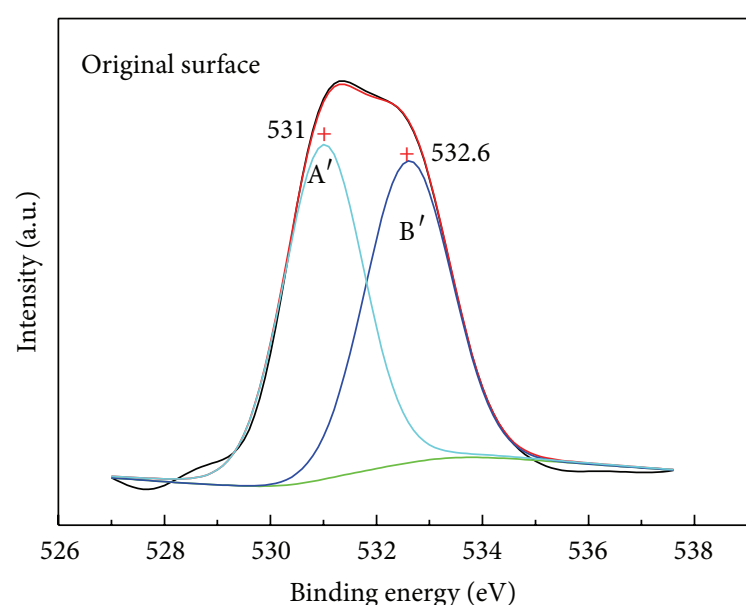

(a)

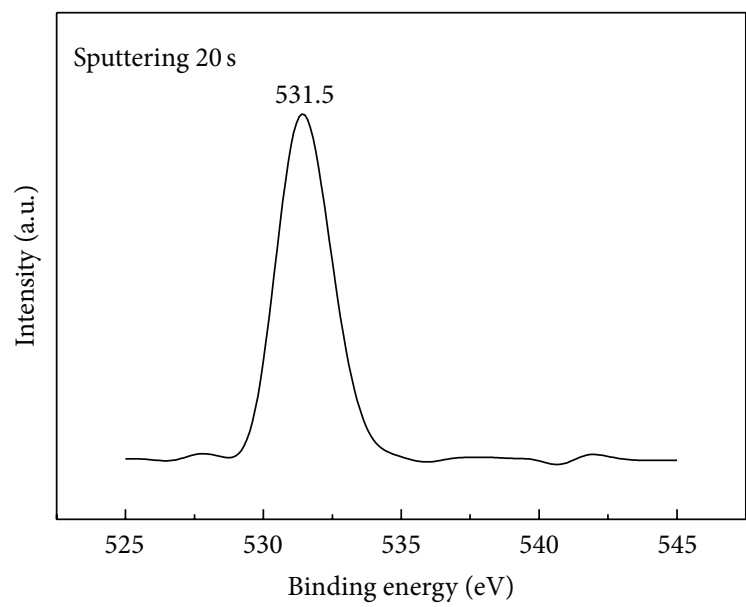

(c)

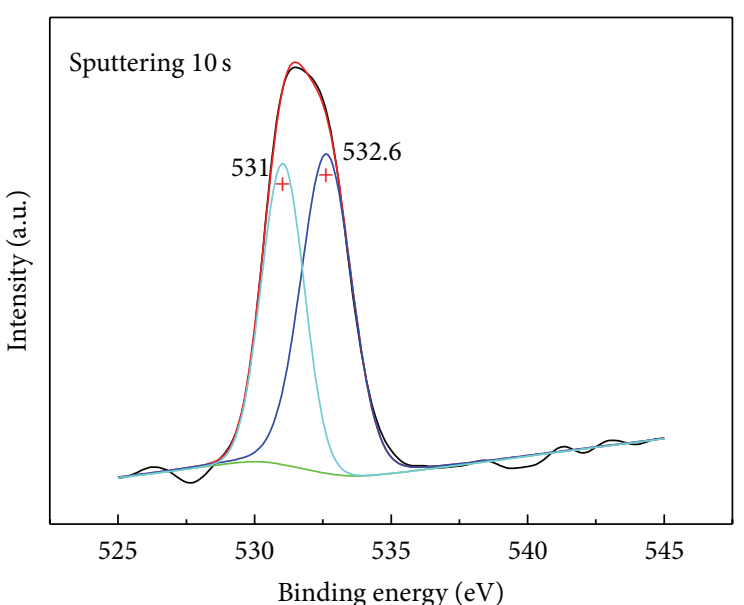

(b)

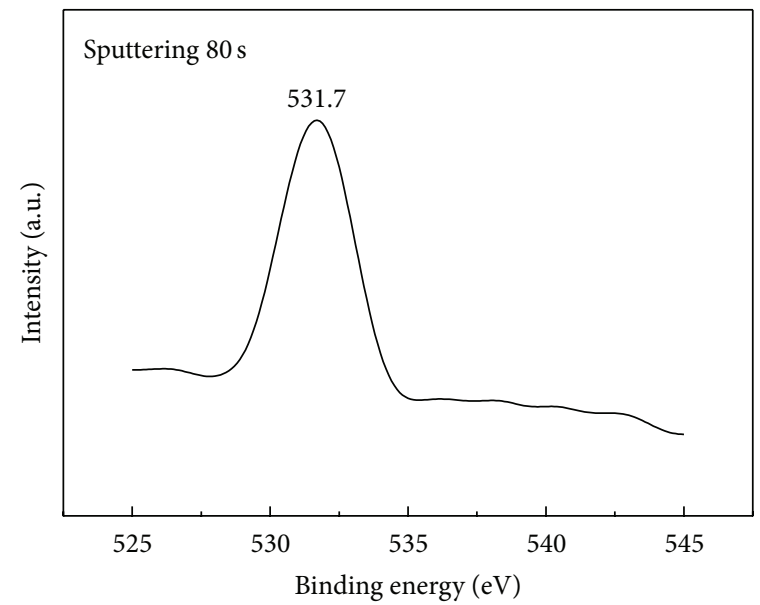

(d)

Figure 6: O 1s spectra of SBZA sample exposure at $170^{\circ} \mathrm{C}$ for $7 \mathrm{~min}$ after etching for (a) $0 \mathrm{~s}$ (initial surface), (b) $10 \mathrm{~s}$, (c) $20 \mathrm{~s}$, and (d) $80 \mathrm{~s}$.

According to the atomic concentration depth profile of SBZA etched for $0 \mathrm{~s}$, it is found that there are mainly $\mathrm{Zn}$ and $\mathrm{Al}$ in the outer surface of the oxidation film. And considering that $\mathrm{O}$ chemically bounded with $\mathrm{Zn}$ located at $530.7 \mathrm{eV}, \mathrm{O}$ bounded with $\mathrm{Al}$ located at $532.6 \mathrm{eV}$, the $\mathrm{OM}$ oxygen should be mainly $\mathrm{ZnO}$ and $\mathrm{Al}_{2} \mathrm{O}_{3}$ with a little $\mathrm{Bi}$ and $\mathrm{Sn}$ inside. Peak B which corresponded to adsorbed oxygen $(532.5 \mathrm{eV})$ [17] and $\mathrm{Al}_{2} \mathrm{O}_{3}$ [19] that could not be resolved becomes lower and totally disappears after etching for $20 \mathrm{~s}$. That is, the film of SBZA sample is much denser than the surface film of SBZ sample, because the time getting to zero for physical adsorbed oxygen in SBZ sample requires $60 \mathrm{~s}, 40 \mathrm{~s}$ more than SBZA sample.

It is noteworthy that peak $\mathrm{A}^{\prime}$ shifts from $531 \mathrm{eV}$ to higher binding energy, $531.5 \mathrm{eV}$ after $20 \mathrm{~s}$ etch time, then $531.7 \mathrm{eV}$ at the etching time of $80 \mathrm{~s}$, which might be also ascribed to the stronger $\mathrm{Sn}-\mathrm{O}$ bond similar to the SBZ sample.

Sn 3d spectra along the film depth are shown in Figure 7. Similar to the results for SBZ in Figure 3, the peak position of $\mathrm{Sn} 3 \mathrm{~d} 5 / 2$ of the original outer surface is positioned at $487.03 \mathrm{eV}$. However, after $80 \mathrm{~s}$ of etching, Sn $3 \mathrm{~d}$ peak shifts slightly to $486.31 \mathrm{eV}$ first and then maintains its position till the tin oxide disappears. Both the binding energy of the outer surface and the subsurface are slightly greater than that of the SBZ oxide film. The possible reason may lie in a strong electron withdrawing group or compounds around the tin atoms, which changed the chemical conditions resulting by the trace amount of $\mathrm{Al}$ addition. After removing $36 \mathrm{~nm}$ from the surface by etching, no oxide has been detected by XPS. The peak position of metallic tin is located at $484.86 \mathrm{eV}$ as shown in Figure 7(d).

Figure 8 shows the XPS spectra of $\mathrm{Al} 2 \mathrm{p}$ depth profiles of oxide film in SBZA sample. The XPS peak height (Al content can be estimated) on the subsurface of oxidation is higher than that on the outer surface. The detected segregation layer of $\mathrm{Al}$ is very thin, distributed over a depth of about $12-48 \mathrm{~nm}$ from the outer surface. There is no visible $\mathrm{Al}$ peak detected beyond the area. From Figure 8, it is found that an almost invisible peak around $75.1 \mathrm{eV}$ is showing at the outer film surface. After etching for $20 \mathrm{~s}$, a new peak located at $72.2 \mathrm{eV}$ arises corresponding to metal Al. It implies the enrichment behavior of element $\mathrm{Al}$ at the subsurface that the atom $\mathrm{Al}$ 


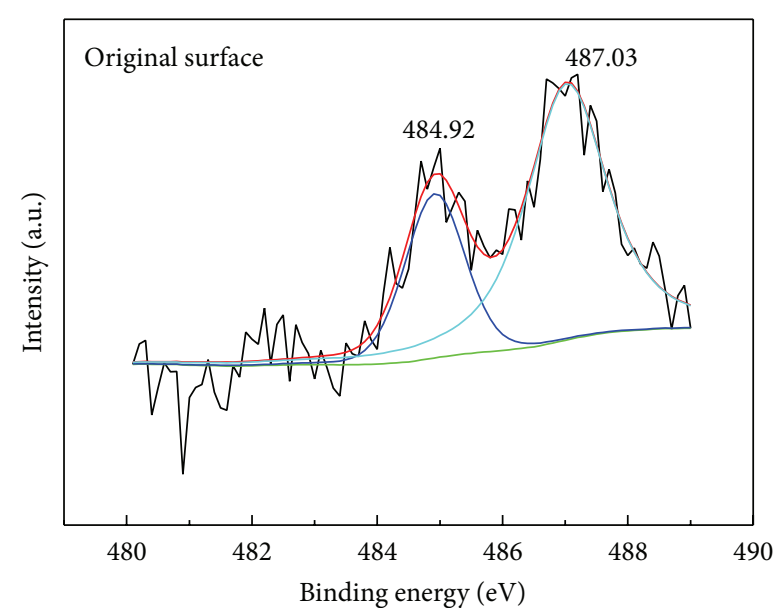

(a)

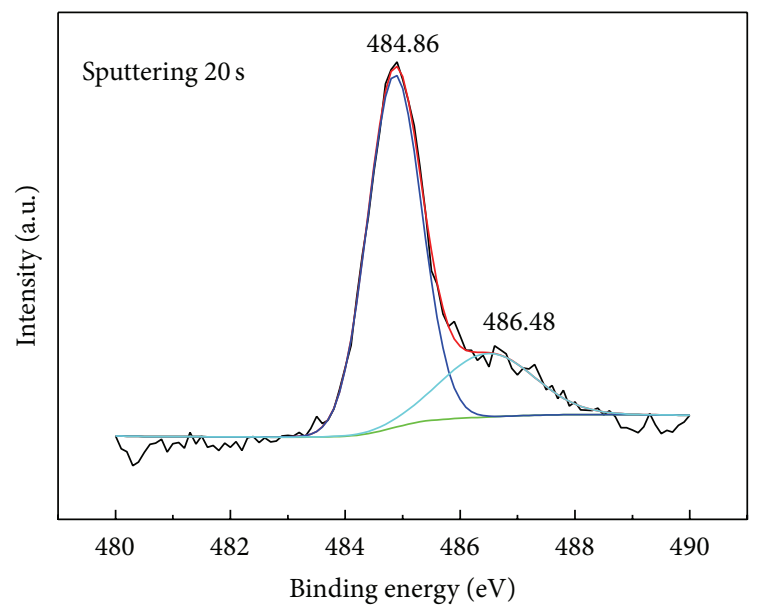

(c)

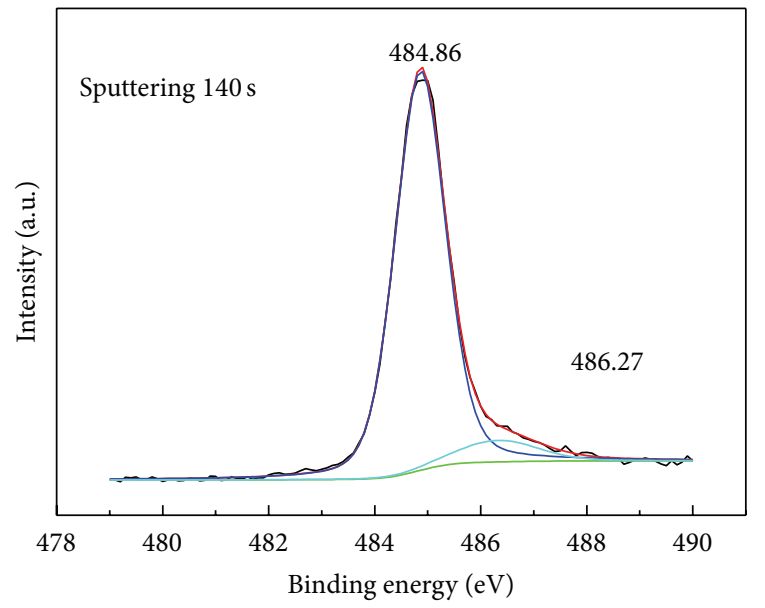

(e)

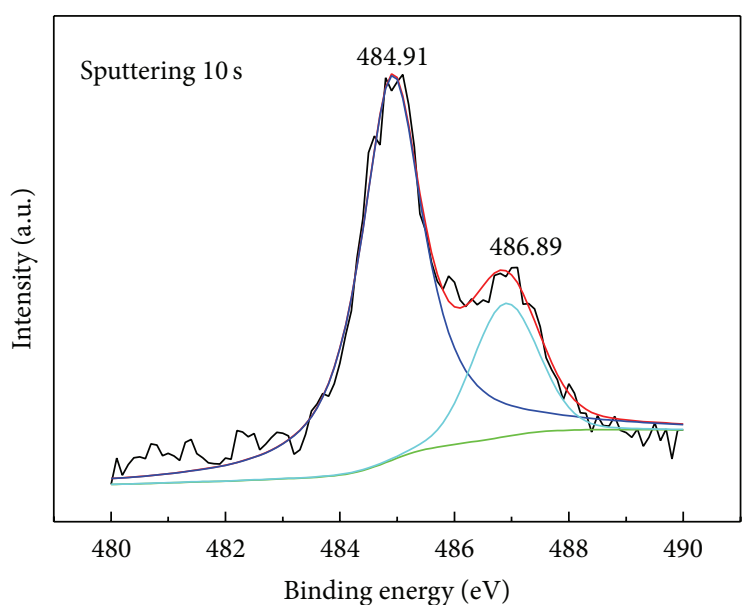

(b)

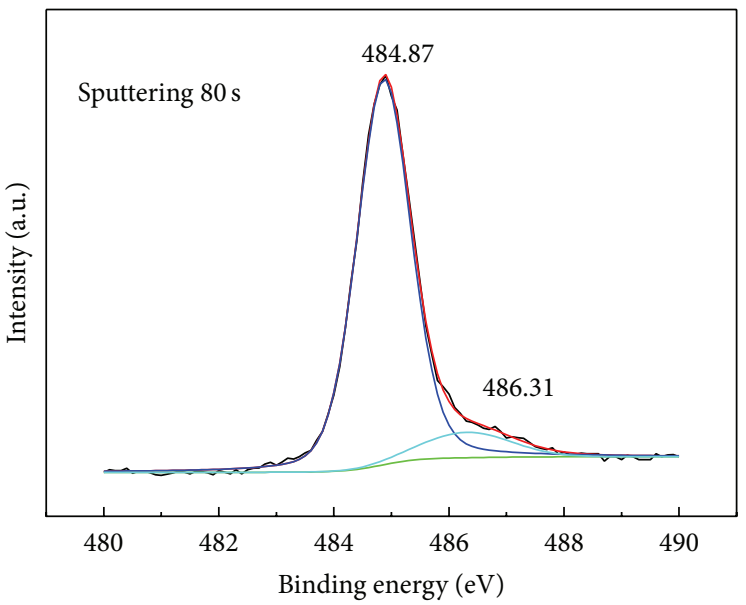

(d)

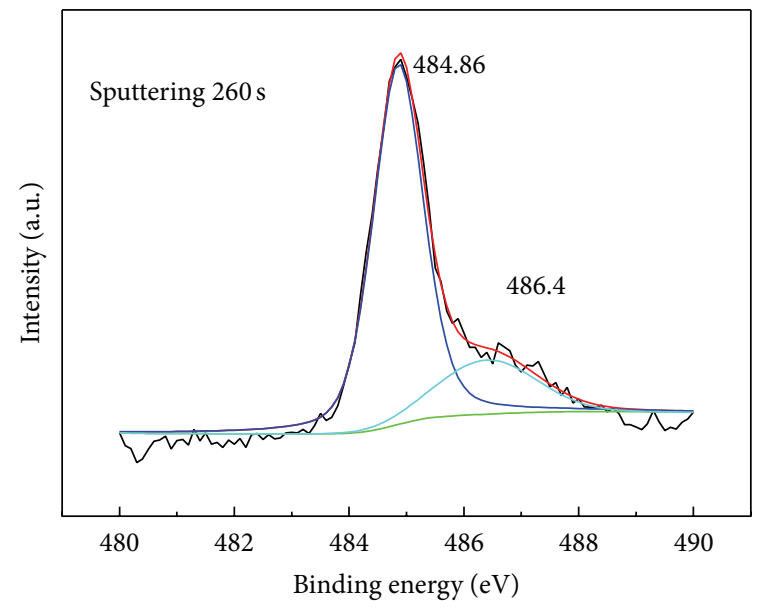

(f)

FIgURE 7: Sn 3d5/2 spectra of SBZA sample exposure at $170^{\circ} \mathrm{C}$ for $7 \mathrm{~min}$ after etching for (a) $0 \mathrm{~s}$ (initial surface), (b) $10 \mathrm{~s}$, (c) $20 \mathrm{~s}$, (d) $80 \mathrm{~s}$, (e) $140 \mathrm{~s}$, and (f) $260 \mathrm{~s}$. 


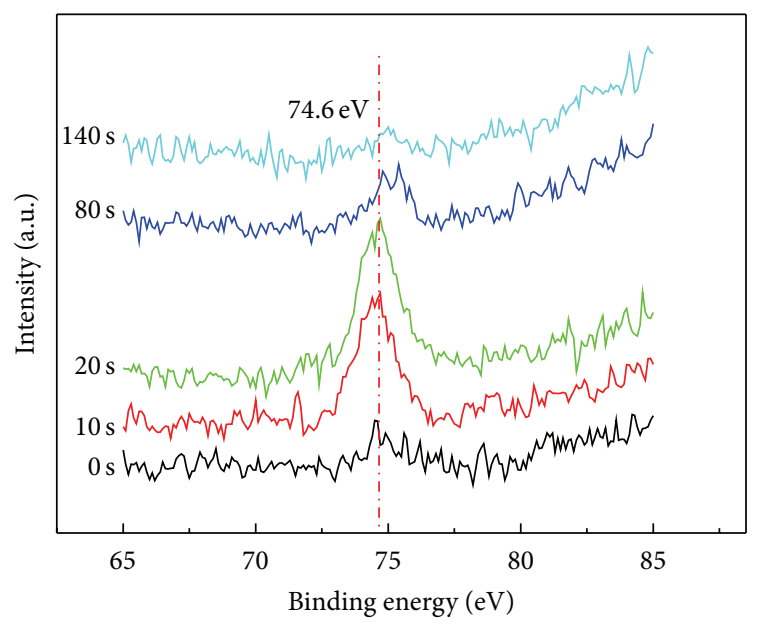

(a)

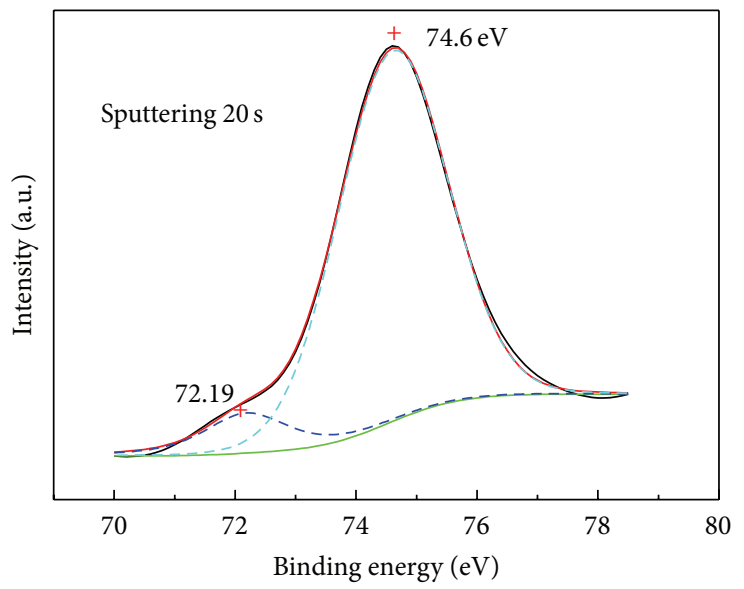

(c)

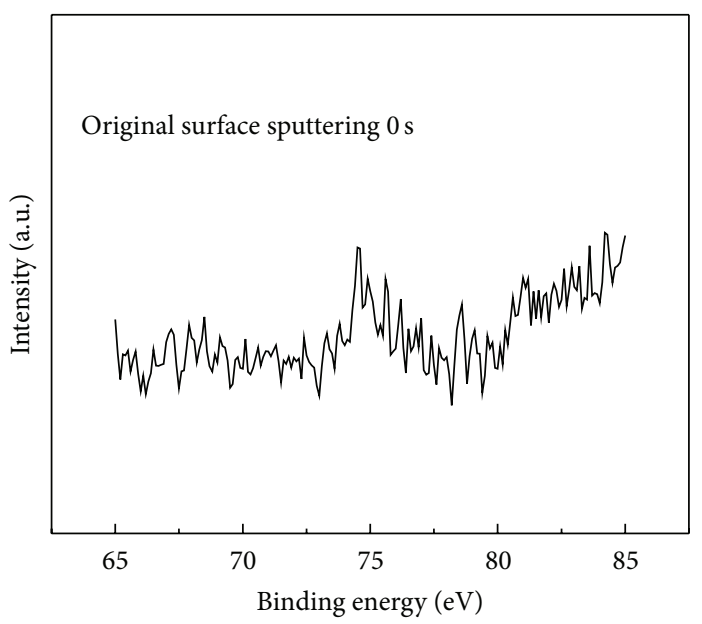

(b)

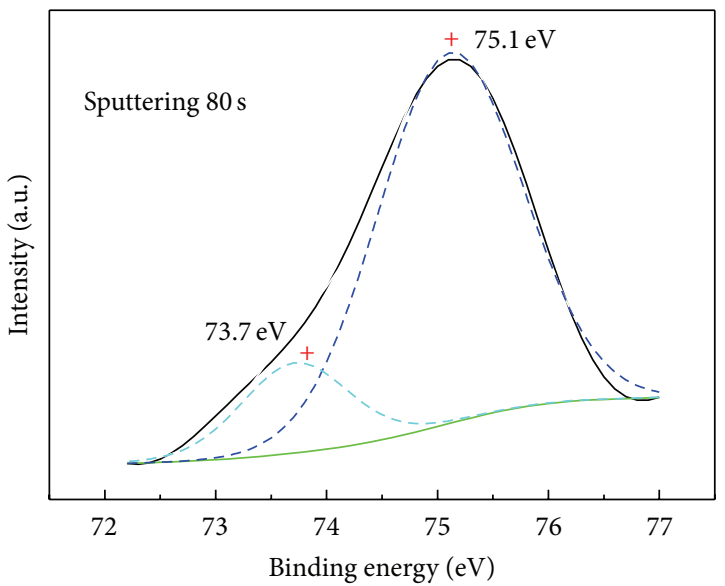

(d)

Figure 8: $\mathrm{Al} 2 \mathrm{p}$ spectra of SBZA sample exposure at $170^{\circ} \mathrm{C}$ for $7 \mathrm{~min}$ after etching for (a) various times from $0 \mathrm{~s}$ to $140 \mathrm{~s}$, (b) $0 \mathrm{~s}$ (initial surface), (c) $20 \mathrm{~s}$, and (d) $80 \mathrm{~s}$.

can be kept as a lower chemical state, $\mathrm{Al}^{0}$. While the etching time increases to $80 \mathrm{~s}$, both kinds of peaks shift to higher energy direction. It suggests that there is a new chemical state of $\mathrm{Al}$ in the oxide. Based on [18], this peak position for Al 2p approaches that of $\mathrm{Al}_{2} \mathrm{O}_{3}$, with $0.9 \sim 1.9 \mathrm{eV}$ deviation which might result by $\mathrm{Sn}$ and Bi dissolved in the oxidation film. However, further research is necessary to clarify the $\mathrm{Al}$ mechanism in the protective oxide film.

Combined with the result of semiquantitative analysis (see Figure 2), it is reasonable to propose that there is a triple-layer oxidation film structure. The outer surface should mainly comprise of $\mathrm{O}$ in physical status and $\mathrm{ZnO}$ with about $6 \mathrm{~nm}$ in thickness. The subsurface should be $\mathrm{ZnO}$ and $\mathrm{Al}_{2} \mathrm{O}_{3}$ doped with $\mathrm{Sn}^{4+}$ and $\mathrm{Bi}^{3+}$ to about $30-84 \mathrm{~nm}$ thickness according to $\mathrm{Al}$ element getting to almost zero and $\mathrm{Sn}$ metal contents almost being the main in all forms of Sn, which could be a protective film to prevent further oxidation of the molten solder alloy in atmosphere condition. And the inner remaining thickness of the film layer should be $(\mathrm{Sn}, \mathrm{Bi}$, and $\mathrm{Zn)} \mathrm{O}$ as a transition layer.

\section{Conclusion}

The properties of the oxide film that forms on liquid SBZ solder and the effect of $\mathrm{Al} / \mathrm{P}$ addition on the film properties were investigated by XPS depth profiling at $170^{\circ} \mathrm{C}$ for $7 \mathrm{~min}$ :

(1) It was found that the thickness of the SBZ oxide was approximately $216 \mathrm{~nm}$. Further XPS analysis revealed that the oxide film close to the substrate mainly composed of $\mathrm{Sn}^{2+}$ oxides which consisted mostly of $\mathrm{Zn}^{2+}$ oxides near the free surface. The amount of $\mathrm{Sn}^{4+}$ and $\mathrm{Bi}^{3+}$ oxides generated near the film surface was found to be similar to the three types of samples.

(2) With $0.005 \mathrm{wt} . \% \mathrm{Al}$ addition to SBZ creating a SBZA alloy, a triple-layer oxidation film structure can be observed. The outer surface should mainly comprise of physical absorbed $\mathrm{O}$ and $\mathrm{ZnO}$. Oxides of $\mathrm{Zn}$ and $\mathrm{Al}$ are mainly responsible for the formation of the subsurface of SBZA alloy. The oxides of $\mathrm{Sn}$ and $\mathrm{Bi}$ forming the innermost layer also contribute a little 
to the film formation. Considerable $\mathrm{Al}$ segregation occurs towards the surface principally as $\mathrm{Al}_{2} \mathrm{O}_{3}$.

(3) A trace amount of P doped to SBZ could not decrease the thickness of the oxidation film. But the $\mathrm{Zn}$ content in the outer surface of oxidation was decreased. This supports the idea that a minus $\mathrm{P}$ can protect $\mathrm{Zn}$ from excess oxidation.

(4) This work suggests that the solders with $\mathrm{Zn}$ can be considered as a potential alternative with trace amount of $\mathrm{Al}$ addition for low melting point solders, especially when the oxidation of the liquid solder is a concern.

\section{Conflict of Interests}

The authors declare that there is no conflict of interests regarding the publication of this paper.

\section{Acknowledgments}

The authors would like to thank Senior Engineer G. L. Gong in Nokia Corporation and Professor C. Yan in Jiangsu University of Science and Technology for the useful discussion on XPS data analysis. They also express their appreciation to P. Y. Guo for editorial revising. This work was supported by the National Natural Science Fund (51201072).

\section{References}

[1] X. C. Tong, "Thermal interface materials in electronic packaging," in Advanced Materials for Thermal Management of Electronic Packaging, vol. 30 of Springer Series in Advanced Microelectronics, pp. 305-371, Springer, Berlin, Germany, 2011.

[2] L. Zang, Z. Yuan, Y. Zhu, B. Xu, H. Matsuura, and F. Tsukihashi, "Spreading process and interfacial characteristic of Sn-17Bi$0.5 \mathrm{Cu} / \mathrm{Ni}$ at temperatures ranging from $523 \mathrm{~K}$ to $673 \mathrm{~K}$," Colloids and Surfaces A: Physicochemical and Engineering Aspects, vol. 414, pp. 57-65, 2012.

[3] G. F. Ma, H. L. Zhang, H. F. Zhang, H. Li, and Z. Q. Hu, "Interfacial characteristics of molten Bi-43Sn alloy on amorphous and crystalline $\mathrm{Fe}_{78} \mathrm{~B}_{13} \mathrm{Si}_{9}$," Materials Letters, vol. 62, no. 12-13, pp. 1853-1855, 2008.

[4] H. He, H. Zhao, F. Guo, and G. Xu, "Bi layer formation at the anode interface in $\mathrm{Cu} / \mathrm{Sn}-58 \mathrm{Bi} / \mathrm{Cu}$ solder joints with high current density," Journal of Materials Science \& Technology, vol. 28, no. 1, pp. 46-52, 2012.

[5] X. J. Wang, Y. L. Wang, F. J. Wang, N. Liu, and J. X. Wang, "Effects of $\mathrm{Zn}, \mathrm{Zn}-\mathrm{Al}$ and $\mathrm{Zn}-\mathrm{P}$ additions on the tensile properties of Sn-Bi solder," Acta Metallurgica Sinica, vol. 27, no. 6, pp. 1159-1164, 2014.

[6] A. A. El-Daly and A. M. El-Taher, "Improved strength of Ni and $\mathrm{Zn}$-doped $\mathrm{Sn}-2.0 \mathrm{Ag}-0.5 \mathrm{Cu}$ lead-free solder alloys under controlled processing parameters," Materials \& Design, vol. 47, pp. 607-614, 2013.

[7] Y. M. Kim, T. J. Kim, M. Y. Choi, and Y.-H. Kim, "Interfacial reactions between $\mathrm{Sn}-3.0 \mathrm{Ag}-0.5 \mathrm{Cu}$ solder and $\mathrm{Cu}-x \mathrm{Zn}(x=0-$ $35 \mathrm{wt} \%)$ or $\mathrm{Cu}-x \mathrm{Zn}-y \mathrm{Ni}(x=20$ and $25 \mathrm{wt} \%, y=15$ and $10 \mathrm{wt} \%)$ substrates," Journal of Alloys and Compounds, vol. 575, pp. 350358, 2013.
[8] H. J. Lin and T. H. Chuang, "Effects of Ce and $\mathrm{Zn}$ additions on the microstructure and mechanical properties of $\mathrm{Sn}-3 \mathrm{Ag}-$ 0.5Cu solder joints," Journal of Alloys and Compounds, vol. 500, no. 2, pp. 167-174, 2010.

[9] T.-C. Chang, J.-W. Wang, M.-C. Wang, and M.-H. Hon, "Solderability of $\mathrm{Sn}-9 \mathrm{Zn}-0.5 \mathrm{Ag}-1 \mathrm{In}$ lead-free solder on $\mathrm{Cu}$ substrate: part 1. Thermal properties, microstructure, corrosion and oxidation resistance," Journal of Alloys and Compounds, vol. 422, no. 1-2, pp. 239-243, 2006.

[10] K.-L. Lin and T.-P. Liu, "High-temperature oxidation of a SnZn-Al solder," Oxidation of Metals, vol. 50, no. 3-4, pp. 255-267, 1998.

[11] M. L. Huang, N. Kang, Q. Zhou, and Y. Z. Huang, "Effect of $\mathrm{Ni}$ content on mechanical properties and corrosion behavior of $\mathrm{Al} / \mathrm{Sn}-9 \mathrm{Zn}-x \mathrm{Ni} / \mathrm{Cu}$ joints," Journal of Materials Science \& Technology, vol. 28, no. 9, pp. 844-852, 2012.

[12] L. Zhang, S. B. Xue, L. L. Gao et al., "Development of SnZn lead-free solders bearing alloying elements," Journal of Materials Science: Materials in Electronics, vol. 21, no. 1, pp. 1$15,2010$.

[13] P. Ghodsa, O. B. Isgora, J. R. Brownb, F. Bensebaac, and D. Kingstonc, "XPS depth profiling study on the passive oxide film of carbon steel in saturated calcium hydroxide solution and the effect of chloride on the film properties," Applied Surface Science, vol. 257, no. 10, pp. 4669-4677, 2011.

[14] J. Mittal, Y. W. Lin, and K. L. Lin, "Influence of Cu substrate surface oxides and heating rates during reflow on melting point of Sn-3.5Ag solder," Applied Surface Science, vol. 256, no. 11, pp. 3531-3540, 2010.

[15] A.-P. Xian and G.-L. Gong, "Surface oxidation of molten Sn$0.07 \mathrm{wt} \% \mathrm{P}$ in air at $280^{\circ} \mathrm{C}$," Journal of Materials Research, vol. 23, no. 6, pp. 1532-1536, 2008.

[16] D. Briggs and M. P. Seah, Practical Surface Analysis, Wiley, New York, NY, USA, 1983.

[17] J.-M. Song, Y.-M. Cheng, and C.-H. Tsai, "Oxidation of liquid solders for die attachment," Corrosion Science, vol. 52, no. 12, pp. 4011-4016, 2010.

[18] U. S. Mohanty and K. L. Lin, "Effect of Al on the electrochemical corrosion behaviour of $\mathrm{Pb}$ free $\mathrm{Sn}-8.5 \mathrm{Zn}-0.5 \mathrm{Ag}-\mathrm{XAl}-0.5 \mathrm{Ga}$ solder in 3.5\% NaCl solution," Applied Surface Science, vol. 252, pp. 5907-5916, 2006.

[19] G. E. Muilenberg, Handbook of X-Ray Photoelectron Sectroscopy, Perkin-Elmer, Eden Prairie, Minn, USA, 1992.

[20] J. Chastain, Handbook of X-Ray Photoelectron Sectroscopy, PerkinElmer, Waltham, Mass, USA, 1992.

[21] A. Nylund and I. Olefjord, "Surface analysis of oxidized aluminum. 1. Hydration of $\mathrm{Al}_{2} \mathrm{O}_{3}$ and decomposition of $\mathrm{Al}(\mathrm{OH})_{3}$ in a vacuum as studied by ESCA," Surface and Interface Analysis, vol. 21, no. 5, pp. 283-289, 1994. 

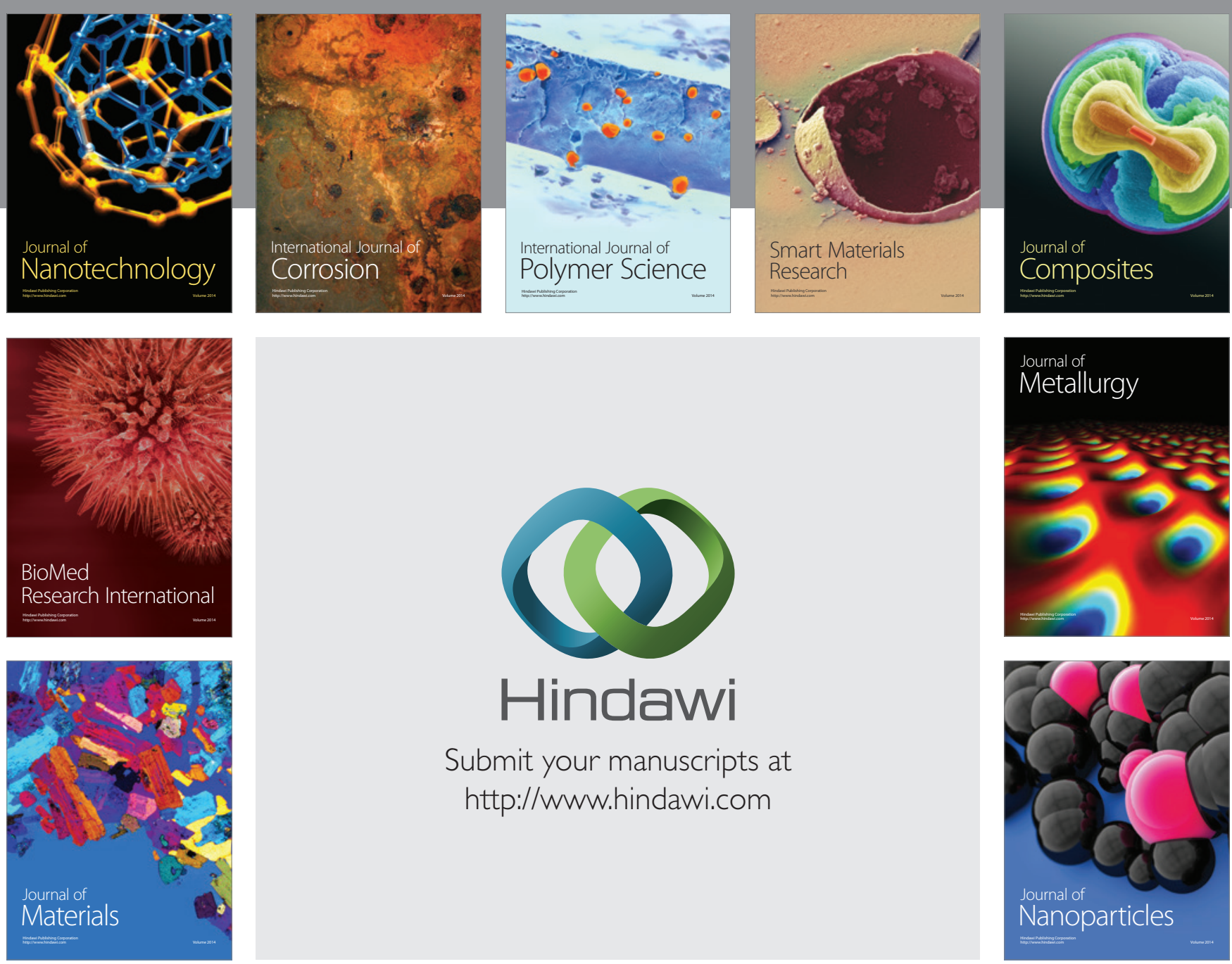

Submit your manuscripts at http://www.hindawi.com
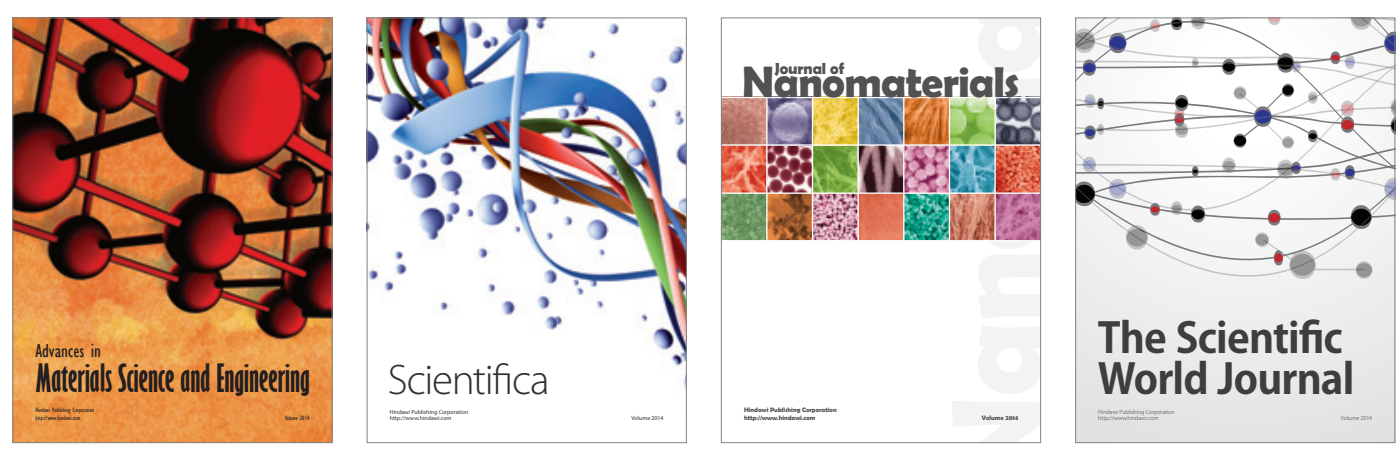

\section{The Scientific World Journal}
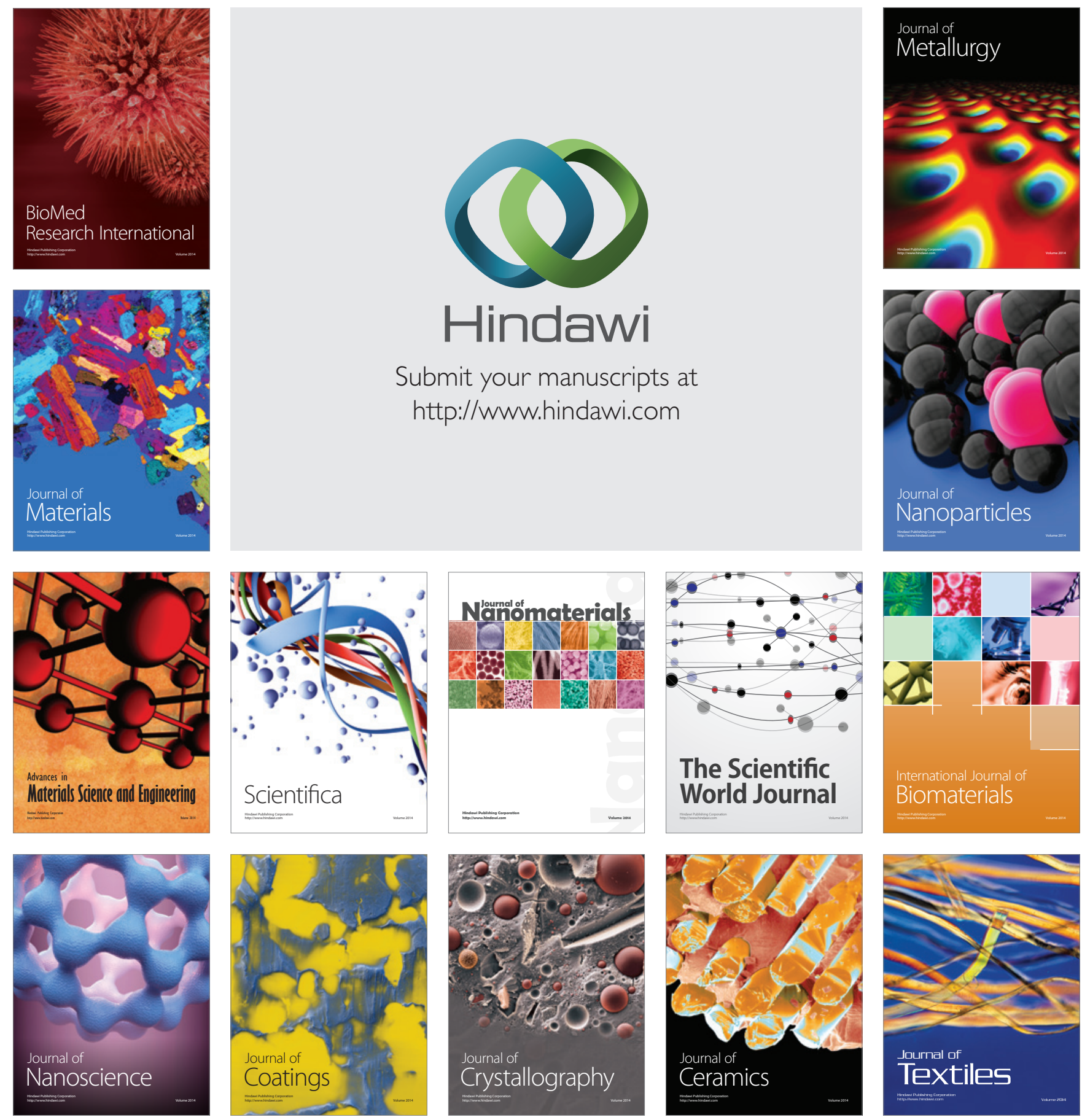